\title{
AJUSTE DE EQUAÇÕES VOLUMÉTRICAS E REDES NEURAIS ARTIFICIAIS NA ESTIMATIVA DO VOLUME DE TAUARI NA FLORESTA NACIONAL DO TAPAJÓS
}

\author{
Ketlen Naiane Freitas dos Santos ${ }^{1}$; Rafael Rode²; Dárlison Fernandes Carvalho de Andrade ; Kleyton \\ Kleber dos Santos Corrêa4; Lucas Sérgio de Sousa Lopes 5 . \\ 1 Universidade Federal do Oeste do Pará, Santarém, Pará, Brasil, ketlennayane@gmail.com \\ 2 Universidade Federal do Oeste do Pará, Santarém, Pará, Brasil, rafaelrode@gmail.com \\ ${ }^{3}$ Instituto Chico Mendes de Conservação da Biodiversidade, Santarém, Pará, Brasil, darlisonicmbio@gmail.com \\ ; ${ }^{4}$ E Universidade Federal do Oeste do Pará, Santarém, Pará, Brasil, kleyton.kleber@hotmail.com \\ ${ }^{5}$ Universidade Federal do Oeste do Pará, Santarém, Pará, Brasil, lucaasergio@gmail.com
}

RESUMO: O objetivo do presente estudo foi comparar as estimativas do volume obtidas por equações de regressão com redes neurais artificiais (RNA) para a espécie Couratari stellata, a partir dos dados de cubagem rigorosa de 1.351 árvores com DAP $\geq 50 \mathrm{~cm}$ de 04 (quatro) Unidades de Produção Anual (UPAs), a saber: Upas 06, 07, 08 e 09, manejadas, respectivamente, em 2011, 2012, 2013 e 2014, da área de manejo florestal da Cooperativa Mista da Floresta Nacional do Tapajós, em área de Floresta Ombrófila Densa de Terra Firme. O processamento dos dados visou selecionar o melhor modelo de regressão considerando as quatro UPAs na área de manejo. A equação com melhor desempenho foi escolhida de acordo com a raiz do erro quadrado médio em porcentagem (RMSE\%), correlação de Pearson e gráfico de resíduos percentuais. Para a seleção da melhor rede e a sua respectiva comparação com a melhor equação de regressão ajustada, as estatísticas utilizadas foram: RMSE\%, correlação de Pearson entre o volume observado e estimado e bias. A equação com melhor desempenho, para todas as UPAs, foi a de Schumacher-Hall sendo posteriormente comparada com a melhor RNA obtida a partir do treinamento dos dados. Verificou-se que ambos os métodos apresentaram estatísticas de ajuste e precisão aceitáveis, com potencial utilização para estimar o volume da espécie Couratari stellata. No entanto, a RNA mostrouse ligeiramente superior pela habilidade de aprender e generalizar o conhecimento adquirido sendo, portanto, recomendada para tal finalidade.

PALAVRAS-CHAVE: Manejo florestal, Romaneio, Volumetria.

\section{ADJUSTMENT OF VOLUMETRIC EQUATIONS AND ARTIFICIAL NEURAL NETWORKS IN THE ESTIMATION OF THE VOLUME OF TAUARI IN THE TAPAJOS NATIONAL FOREST}

ABSTRACT: The objective of this study was to compare the volume estimates obtained by regression equations with artificial neural networks (ANNs) for the species Couratari stellata, from the data of rigorous cubing of 1351 trees with $\mathrm{DBH} \geq 50 \mathrm{~cm}$ from 04 (four) Annual Production Units (APUs), namely: APUs 06, 07, 08 and 09, managed 
respectively in 2011, 2012, 2013 and 2014, of the forest management area of the Mixed Cooperative of the Tapajos National Forest, in an area of terra firme dense ombrophylous forest. Data processing aimed to select the best regression model considering four APUs in the area of management. The best-performing equation was chosen according to the root mean square error in percent (RMSE\%), Pearson's correlation and residuals graph. For the selection of the best network and its comparison with the best regression equation adjusted, the statistics used were: RMSE\%, Pearson's correlation between observed and estimated volume and bias. The best-performing equation for all APUs was the Schumacher-Hall equation, which was then compared to the best ANN obtained from data training. It was found that both methods presented acceptable adjustment and precision statistics, with potential use to estimate the volume of the species Couratari stellata. However, ANN has been shown to be slightly superior by the ability to learn and generalize the acquired knowledge and is therefore recommended for this purpose.

KEYWORDS: Forest management, Romaneio, Volume modeling.

\section{AJUSTE DE LAS VOLUMÉTRICAS ECUACIONES Y NEURALES ARTIFICIALES EN LA ESTIMACIÓN DEL VOLUMEN DE TAUARI EN EL BOSQUE NACIONAL DEL TAPAJÓS}

RESUMEN: El objetivo del presente estudio fue comparar las estimaciones del volumen obtenidas por ecuaciones de regresión con redes neuronales artificiales para la especie Couratari stellata, a partir de los datos de cubrimiento riguroso de 1351 árboles con DAP $\geq 50 \mathrm{~cm}$ de 04 (cuatro) Unidades de Producción Anual (UPAs), a saber: Upas 06, 07, 08 y 09, manejadas, respectivamente, en 2011, 2012, 2013 y 2014, del área de manejo forestal de la Cooperativa Mixta del Bosque Nacional del Tapajós, en área de Bosque Ombrófilo Densa de Tierra Firme. El procesamiento de los datos pretendió seleccionar el mejor modelo de regresión considerando las cuatro UPAs en el área de manejo. La ecuación con mejor desempeño fue elegida de acuerdo con la raíz cuadrada del error medio en porcentaje (RMSE\%), correlación de Pearson y gráfico de residuos porcentuales. Para la selección de la mejor red y su respectiva comparación con la mejor ecuación de regresión ajustada, las estadísticas utilizadas fueron: RMSE\%, correlación de Pearson entre el volumen observado y estimado y bias. La ecuación con mejor desempeño para todas las UPAs fue la de SchumacherHall siendo posteriormente comparada con la mejor ARN obtenida a partir del entrenamiento de los datos. Se verificó que ambos métodos presentaron estadísticas de ajuste y precisión aceptables, con potencial utilización para estimar el volumen de la especie Couratari stellata. Sin embargo, la RNA se mostró ligeramente superior por

Agroecossistemas, v. 10, n. 1, p. 1 - 17, 2018, ISSN online 2318-0188 
la habilidad de aprender y generalizar el conocimiento adquirido, siendo, por lo tanto, recomendada para tal fin.

PALABRAS CLAVE: Manejo florestal, Romaneio, Volumetría.

\section{INTRODUÇÃO}

O volume de madeira é, uma variável útil para avaliar o potencial produtivo e econômico de um povoamento florestal ou, de uma espécie em particular. Entretanto, na Amazônia, a diversidade de espécies que constituem o bioma, associada a heterogeneidade entre árvores com altura e diâmetro diferentes, é mais apropriado realizar os ajustes de equações de volume de forma individual para as espécies, e conforme Soares et al. (2011) aumentar a exatidão das estimativas volumétricas.

As variáveis medidas em campo, como o volume real, diâmetro à altura do peito (DAP) e altura, são usadas para ajustar modelos volumétricos por meio de regressão, sendo selecionado aquele mais apropriado com base em testes estatísticos (RAMOS, 2012).

De acordo com Binoti et al. (2014), apesar de se ter muitas equações propostas para estimar o volume de um povoamento florestal, ainda se faz necessário a inclusão de novos métodos ou modelos para realizar a estimativa dessa variável, levando em consideração os custos que esta etapa representa para o inventário florestal, bem como sua importância para as estimativas volumétricas.

Nesse contexto, as Redes Neurais Artificiais (RNAs) apresentam-se como uma boa alternativa, pois de acordo com Braga et al. (2007) as RNAs têm a capacidade de aprender através de exemplos e de generalizar a informação aprendida, além de extrair informações não apresentadas de forma explícita através de exemplos.

As RNAs são um sistema de computação constituído por um número de elementos de processamento simples, altamente interligadas, para a realização de determinada tarefa (LEITE et al., 2016). As habilidades das redes em aprender e 
generalizar são duas características que tornam possível a resolução de problemas complexos e podem produzir saídas adequadas para entradas que não estavam presentes durante a aprendizagem. Além disso, podem trabalhar e desempenhar bons ajustes utilizando variáveis pouco tradicionais como, por exemplo, a possibilidade de modelagem com variáveis categóricas (HAYKIN, 2001).

Sendo assim, as RNAs são apresentadas como uma boa alternativa para resolver problemas na área florestal, podendo ser utilizada em diversas situações a exemplo do uso para estimação do volume de árvores (BINOTI et al., 2014; CORDEIRO et al., 2015; GÖRGENS et al., 2009; LEAL et al., 2015; SILVA et al., 2009). Entretanto, o uso de novas técnicas na estimativa do volume requer testes em casos específicos, e seus resultados precisam comparados quanto à exatidão desta estimativa e ainda, a facilidade de uso.

Diante do exposto, o presente estudo tem por objetivo comparar as estimativas volumétricas obtidas com os ajustes de modelos de regressão e a partir redes neurais artificiais (RNAs), a fim de verificar o melhor método para estimativa desta variável para a espécie Tauari (Couratari stellata A. C. Smith).

\section{MATERIAL E MÉTODOS}

A área de estudo localiza-se na Floresta Nacional do Tapajós, município de Belterra - PA, nas proximidades dos quilômetros 67 e 83 da rodovia BR 163 (Santarém-Cuiabá), onde uma cooperativa de moradores tradicionais da Unidade de Conservação desenvolve suas atividades de manejo florestal. As informações necessárias para o estudo foram obtidas de 04 Unidades de Produção Anual (UPAs), localizadas na área de manejo florestal, sendo: UPAs 06, 07, 08 e 09, demarcadas, respectivamente, em 2011, 2012, 2013 e 2014.

O clima da região é classificado como Ami no sistema Köppen, ou seja, tropical úmido com variação térmica anual inferior a $5^{\circ} \mathrm{C}$, apresentando temperatura média anual de $25,5^{\circ} \mathrm{C}$, umidade relativa média de 90\% e 
precipitação anual média de 1820 mm, concentrada especialmente entre os meses de janeiro e maio (CORDEIRO et al., 2017). Os solos predominantes na Floresta Nacional do Tapajós são do tipo Latossolos Amarelos distróficos, caracterizados por diferentes texturas, geralmente profundos, ácidos, friáveis e revestidos por florestas densas, o tipo de vegetação predominante é o de Floresta Ombrófila Densa (ESPÍRITOSANTO et al., 2005).

Os dados de cubagem rigorosa (romaneio) foram obtidos junto a Cooperativa Mista da Floresta Nacional do Tapajós (COOMFLONA), que alimenta sua base de dados após cada colheita das UPAs com a mensuração de todas de diâmetro e comprimento das toras extraídas na respectiva área. Além da medição, as toras são identificadas para controle na cadeia de custódia.

Os dados utilizados para o presente estudo foram também utilizados por Oliveira et al. (2017) para a realização de ajustes volumétricos para a espécie em questão, os quais recomendaram a aplicação de novos métodos, como as redes neurais artificiais, para emprego em futuros trabalhos sobre esta espécie, com intuito de amenizar os efeitos de tendência encontrados nos modelos de regressão pelo estudo supracitado.

A análise de dados das quatro Unidades de Produção Anual foi realizada com auxílio de planilha eletrônica, com os softwares Excel ${ }^{\circledR}$ 2013 para as análises de regressão dos modelos lineares, Statistica 7 (STATSOFT, 2007) para ajuste do modelo não linear (Takata) e Neuro ${ }^{\circledR}$ 4.0 para o treinamento das redes neurais artificiais.

O processamento dos dados foi realizado em 2 etapas: seleção da melhor equação de regressão para todas as UPAs e seleção da melhor RNA para todas as UPAs para posterior comparação entre estes dois métodos. Para estas etapas, o banco de dados foi dividido em duas partes: $70 \%$ dos dados para o ajuste totalizando 946 árvores de Couratari stellata, e $30 \%$ para a validação com total de 405 árvores, de acordo com as classes diamétricas dos 
indivíduos. O conjunto de dados de validação se torna necessário para a utilização e estudo das RNAs, visto que é através deste conjunto que será avaliado o desempenho da rede, bem como, a identificação de tendências de supertreinamento (overfitting) e treinamento insuficiente (underfitting) (HAYKIN, 2001).

Para a construção das redes neurais artificiais, foram realizados vários treinamentos visando a obtenção de arquiteturas de redes mais adequadas para estimação do volume comercial de Couratari stellata. As variáveis de entrada foram o DAP e a altura comercial e como variável categórica foi utilizada a identificação da UPA, e o volume comercial como variável de saída. Foram treinadas 50 redes do tipo Multilayer Perceptron (MLP) com 10 neurônios na camada oculta. $\bigcirc$ algoritmo utilizado foi o Resilient Propagation (RPROP+) com função de ativação sigmoide para as camadas oculta e de saída.

Foram escolhidas cinco equações para o ajuste volumétrico de simples e dupla entrada para Couratari stellata (tauari), sendo dois de entrada simples, Husch e Kopezky-Gehrardt, e três de entrada dupla, Schumacher-Hall, Spurr e Takata (Tabela 1).

Para a seleção da melhor equação volumétrica foram analisados os seguintes parâmetros estatísticos: correlação de Person (r) entre volume observado e volume estimado, raiz do erro quadrado médio em percentagem (RMSE\%) e análise gráfica dos resíduos da regressão dos erros percentuais.

Para a seleção da melhor rede e a sua respectiva comparação com a melhor equação de regressão ajustada, as estatísticas utilizadas para comparação foram: RMSE\%, correlação de Pearson entre o volume observado e estimado e bias. A rede selecionada foi aplicada para os dados de todas as UPAs separados para validação (generalização) e comparada com a melhor equação volumétrica de acordo com as estatísticas anteriormente citadas. 
Tabela 1. Modelos volumétricos ajustados.

\begin{tabular}{|c|c|c|}
\hline Número & Modelos & Autor \\
\hline 1 & $\ln (V)=\beta 0+\beta 1 \ln (D)+\varepsilon$ & Husch \\
\hline 2 & $V=\beta 0+\beta 1\left(D^{2}\right)+\varepsilon$ & Kopezky - Gehrhardt \\
\hline 3 & $\ln (V)=\beta_{0}+\beta_{1} \ln (D)+\beta_{2} \ln (H)+\varepsilon$ & Schumacher-Hall \\
\hline 4 & $V=\beta_{0}+\beta_{1}\left(D^{2} \cdot H\right)+\varepsilon$ & Spurr \\
\hline 5 & $V=d^{2} h / \beta 0+\beta 1(D)+\varepsilon$ & Takata \\
\hline
\end{tabular}
comercial, em m; $\beta 0$, $\beta 1$ e $\beta 2$ =parâmetros do modelo; ln= logaritmo neperiano; e $\varepsilon$ = erro aleatório.

$$
\begin{array}{r}
r_{y \hat{y}}=\frac{\operatorname{cov}(Y, \hat{Y})}{\sqrt{s^{2}(Y) s^{2}(\bar{Y})}} \\
R M S E \%=\frac{100}{\bar{Y}} \sqrt{\frac{\sum\left(Y_{i}-\hat{Y}_{i}\right)^{2}}{n}} \\
\text { Resíduo\% }=\frac{s y x}{\hat{Y}} * 100
\end{array}
$$

Em que: $\widehat{Y}_{i}=$ volume estimado da $i$-ésima árvore; $Y_{i}=$ volume observado da $i$-ésima árvore; $\mathrm{n}=$ número total de observações; $\bar{Y}=$ volume médio observado; $R M S E \%$ = raiz do erro quadrado médio em percentagem; $\hat{Y}=$ média aritmética da variável dependente (volume observado).

Para validação das equações, volumes observados e estimados das realizou-se o teste Qui-quadrado $\left(\chi^{2}\right)$ árvores não utilizadas nos ajustes, para testar as diferenças entre os conforme equação:

$$
\chi^{2} \text { calculado }=\frac{\sum\left(Y_{i}-\widehat{Y}_{i}\right)^{2}}{\widehat{Y}_{i}}
$$

\section{RESULTADOS E DISCUSSÃO}

Os resultados dos ajustes e coeficientes das equações de volume testadas para Couratari stellata são apresentados na Tabela 2. Pelos resultados dos maiores coeficientes de correlação (r) e menores raiz do erro quadrado médio em percentagem (RMSE\%), observa-se que os melhores ajustes foram para os modelos de Schumacher-Hall e Spurr. 
Na Figura 1 observa-se os dois distribuição gráfica dos resíduos em modelos supracitados que porcentagem em relação ao volume apresentaram melhores ajustes de observado.

Tabela 2. Coeficientes ajustados e parâmetros estatísticos de ajuste e precisão para estimativas volumétricas do povoamento de C. stellata nas quatro unidades de produção anual, localizadas no município de Belterra/Pará.

\begin{tabular}{lcc|c|ccc}
\hline \multirow{2}{*}{ Autores } & \multicolumn{3}{c|}{ Coeficientes } & \multirow{2}{*}{$r_{v v}$} & RMSE\% & R$^{2}$ ajus. \\
\cline { 2 - 4 } & B0 & B1 & B2 & & & \\
\hline Husch & $-4,745974$ & 1,519522 & - & 0,66 & 23,81 & 0,93 \\
Kopezky-G. & 2,088158 & 0,000761 & - & 0,66 & 23,71 & 0,93 \\
Schumacher & $-6,808519$ & 1,398008 & 0,830847 & 0,78 & 19,56 & 0,95 \\
Spurr & 2,237278 & 0,000032 & - & 0,78 & 19,67 & 0,95 \\
Takata & 37281,920042 & 0,036061 & - & 0,77 & 19,96 & 0,95 \\
\hline
\end{tabular}

$r_{w v}=$ coeficiente de correlação de Person; RMSE\% = raiz do erro quadrado médio em percentagem; $\beta_{0}$, $\beta_{1}, \beta_{2}$ = parâmetros da regressão; $R^{2}$ ajus $=R^{2}$ ajustado.

De acordo com os gráficos acima observa-se que o modelo de Schumacher-Hall apresentou maior homogeneidade na distribuição dos resíduos, e menor frequência dos mesmos nas classes de maior erro. No entanto, verifica-se pontos de subestimativa e superestimativa dos volumes pelos dois modelos comparados. Para ambos os modelos de regressão houve uma tendência de superestimação para os volumes de até $5 \mathrm{~m}^{3}$ e subestimação a partir de $10 \mathrm{~m}^{3}$.
No que diz respeito a estudo em floresta nativa, Silva-Ribeiro et al. (2014) ao realizarem um estudo na Floresta Nacional do Tapajós sobre seccionamento para cubagem e escolha de equação de volume, reportaram que os modelos de Schumacher e Spurr, assim como no presente estudo, apresentaram melhores medidas de ajuste e precisão, sendo recomendado pelos autores a utilização de ambos na forma logarítmica para a floresta no geral e para três espécies em particular- 
maçaranduba, jarana e jatobá. Apesar de ambos os modelos de regressão apresentarem resultados satisfatórios, a equação de Schumacher-Hall se sobressaiu de acordo com os critérios de avaliação pré-estabelecidos.

Figura 1. Modelos com melhores ajustes de distribuição gráfica dos resíduos em porcentagem do volume real para Couratari stellata nas quatro unidades de produção anual, Floresta Nacional do Tapajós.
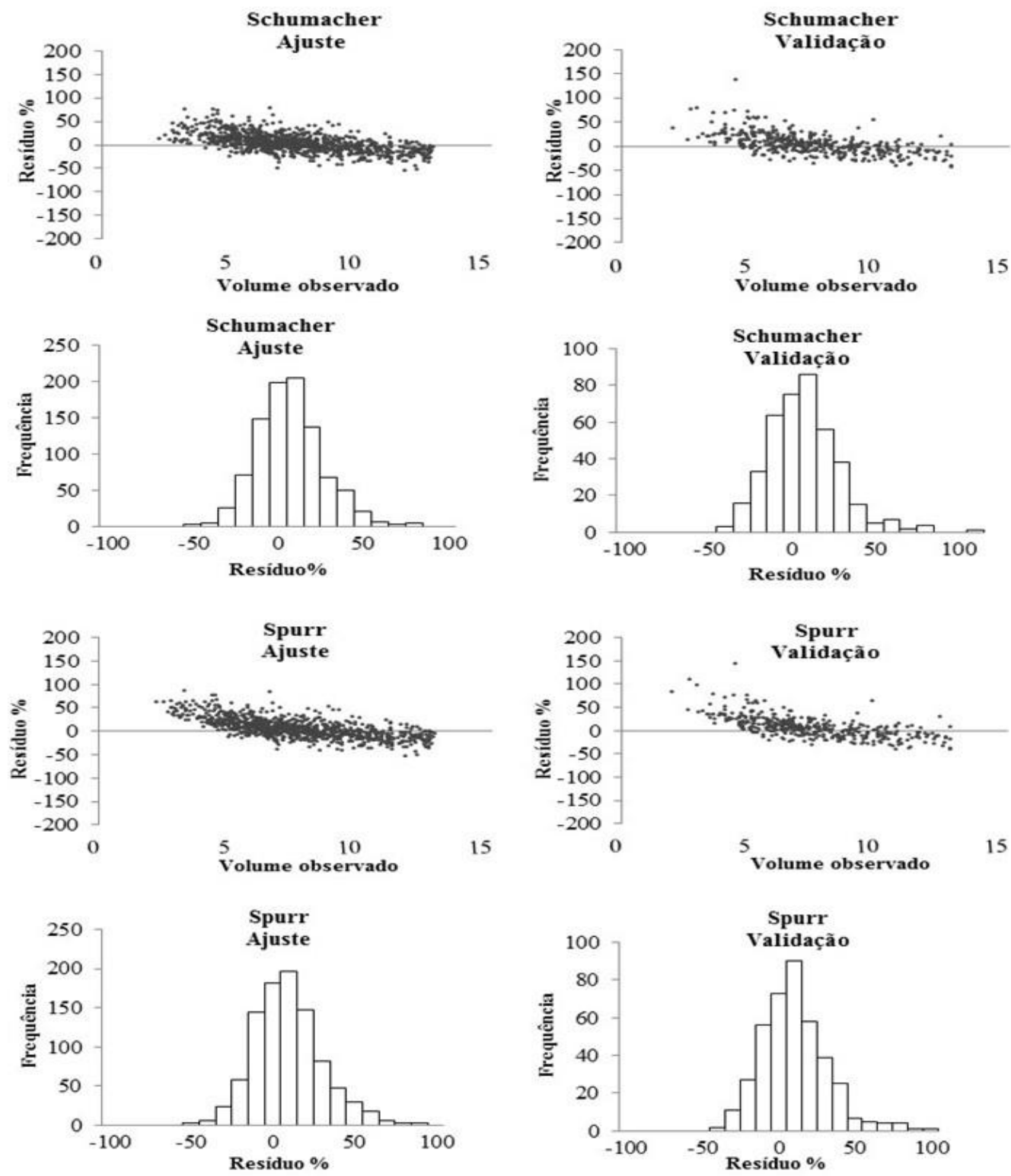
De acordo com Campos e Leite (2013) o modelo de Schumacher e Hall é um dos mais difundidos na área florestal, devido às suas propriedades estatísticas, uma vez que resulta em estimativas quase sempre não tendenciosas. Observando-se melhor desempenho deste em relação a outros modelos quando comparados no presente estudo, com verificado no estudo de Colpini et al. (2009) os quais constataram que o modelo de Schumacher-Hall foi mais preciso para estimar o volume das árvores do estudo para uma área de floresta ombrófila aberta na região noroeste de Mato Grosso, bem como o trabalho realizado por Mendonça et al. (2015) os quais constataram que o modelo de Schumacher- Hall foi mais preciso que o modelo de Spurr, para a estimativa do volume das espécies plantadas de Pinus. Ademais, Barreto et al. 2014, também obtiveram bons ajuste de volume com a equação de Schumacher-Hall em seu estudo realizado para apoio ao manejo comunitário de empreendimento florestal no município de Anapu, Pará.

Para os dados utilizados no ajuste das equações, também foram utilizados nos treinamentos das 50 RNAs. Destas, a RNA com melhor desempenho foi de arquitetura 3-10-1, com duas variáveis de entrada (DAP e Altura) e com a identificação da UPA como variável qualitativa. A comparação foi realizada de acordo com as estatísticas apresentadas na Tabela 4.

Tabela 4. Comparação entre as estatísticas das RNAS x Equações Volumétricas.

\begin{tabular}{lccc|ccc}
\hline & \multicolumn{3}{c}{ Ajuste } & \multicolumn{3}{c}{ Validação } \\
\hline Modelo & RMSE\% & $r_{\mathrm{v}}$ & Bias & RMSE\% & $r_{\mathrm{w}}$ & bias \\
\hline 3-10-1 & 18,31 & 0,812335 & 0,002843 & 20,76 & 0,746430 & 0,002842 \\
Schumacher-Hall & 19,56 & 0,784620 & 0,130963 & 20,60 & 0,751833 & 0,105616 \\
\hline
\end{tabular}

RMSE\% = Raiz do erro quadrado médio em porcentagem; $r_{w}=$ Correlação entre o volume observado e estimado. 
Ao analisar a Tabela 4 é possível observar que ambos os métodos apresentaram estatísticas de ajuste e precisão aceitáveis. No entanto, o desempenho das redes neurais destacou-se para os dados do ajuste por apresentar menor raiz do erro quadrado médio (RMSE\%), maior coeficiente de correlação $\left(r_{w}\right)$ e menor bias. Ao verificar as estatísticas calculadas para os dados de validação é observada uma pequena diferença em relação as estatísticas de precisão entre a RNA e o modelo de regressão, reafirmando que ambos obtiveram um bom desempenho na estimativa volumétrica para o conjunto de dados, apresentando nesse último caso, o modelo de Schumacher-Hall melhor desempenho.

Na Figura 3 observa-se a análise gráfica do resíduo em função do volume observado para o modelo de regressão e a rede neural artificial para os dados do ajuste.

Figura 3. Distribuição dos resíduos em relação ás estimativas do modelo de regressão e redes neurais artificiais, para todas as UPAs utilizadas no treinamento (ajuste).

RNA 3-10-1

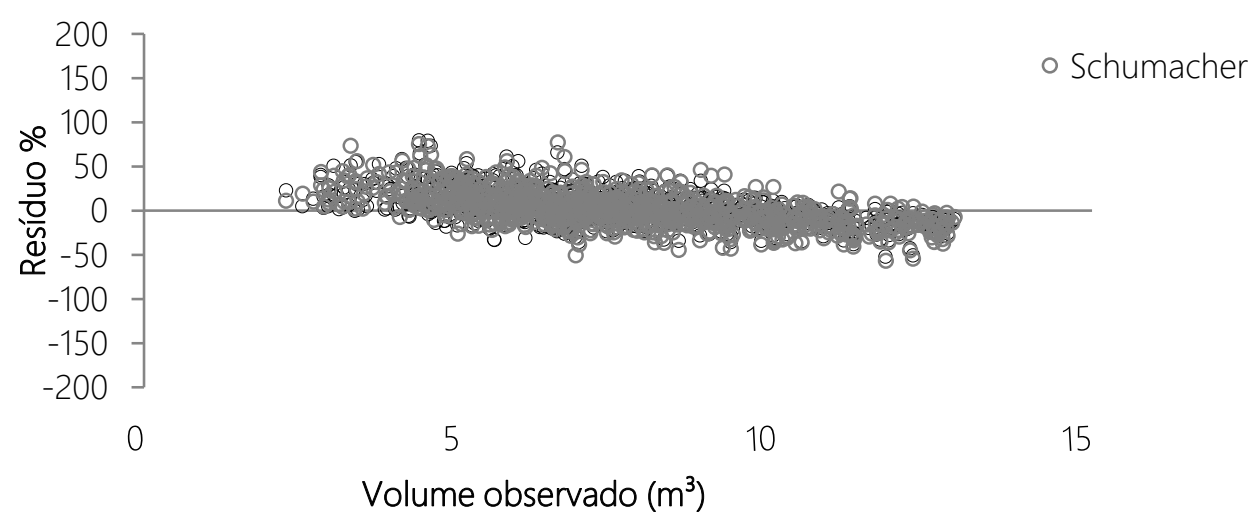


A partir da análise gráfica dos resíduos fica evidenciado que a rede neural artificial foi ligeiramente superior ao modelo de regressão, visto que a dispersão dos resíduos da de Schumacher-Hall apresentou maior heterogeneidade na dispersão residual e mais pontos de superestimação e subestimação quando comparado à RNA. Diante disso, verifica-se a importância desta análise, pois este procedimento é um quesito de suma importância para avaliação de uma equação visto que, erros de tendência podem ocorrer em determinada amplitude de classe da variável resposta, sem ser detectadas pelas estatísticas que medem a exatidão (DRAPER; SMITH, 1998; LEAL et al., 2015).

A ligeira superioridade supracitada no ajuste das redes neurais artificiais, está atrelada, entre outros fatores, ao fato das RNAs produzirem bons resultados utilizando variáveis pouco tradicionais nos ajustes como, por exemplo, a possibilidade de modelagem com variáveis categóricas, também chamadas de qualitativas e, a celeridade no aprendizado e na habilidade de generalizar das RNAs o que possibilita assim a resolução de problemas mais complexos (HAYKIN, 2001). Ademais, Martins et al. (2016) cita que as RNA têm a vantagem de serem capazes de ajustar dados com relações não lineares sem especificar previamente um modelo, diferindo da abordagem por regressão.

O reflexo do bom desempenho da rede neural artificial em relação ao modelo de regressão na estimativa do volume, pode ainda ser visualizado na Figura 4, onde é possível notar que em relação ao modelo de Schumacher a RNA apresentou desvios menores em relação ao volume observado total para as quatro UPAs utilizadas no treinamento.

Alguns trabalhos têm demonstrado o potencial do uso de RNA comparados a procedimentos tradicionais no meio florestal (MARTINS et al., 2017; SCHIKOWSKI et al., 2015; SILVA et al., 2016). Leal et al. (2015) realizou a estimativa de volume em 
plantio de Eucalyptus urophylla concluindo que o desempenho das RNAs foi superior quando comparado ao advindo da equação de regressão e, portanto, indicando a utilização das mesmas para estimativas volumétricas. Assim como constatado pelo trabalho de Silva et al. (2009), ao avaliarem o desempenho das RNAs na estimativa do volume de madeira de eucalipto, concluindo que as RNAs tiveram boa adequação as situações testadas e recomendaram 0 uso destas para previsão volumétrica.

Figura 4. Desempenho das redes neurais e regressão para a soma dos volumes estimados para as quatro UPAs utilizadas no ajuste.

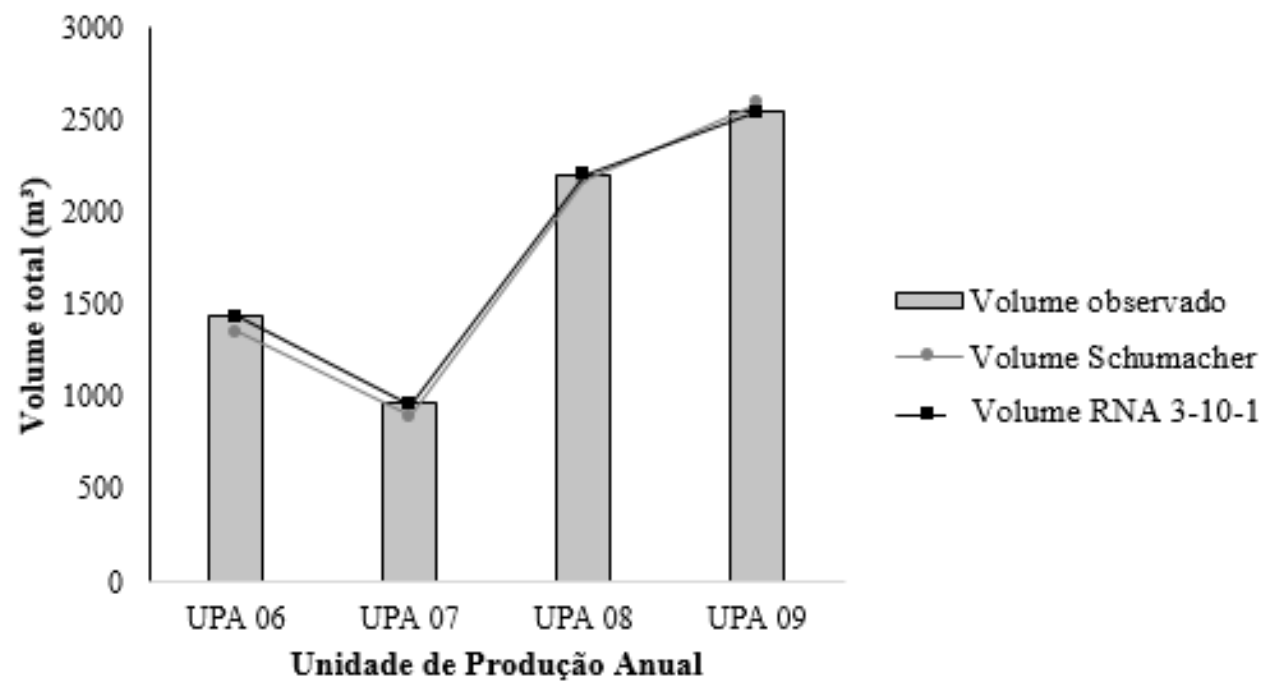

As redes neurais apresentaram um bom desempenho para a estimativa volumétrica da espécie em estudo, podendo ser indicada como uma alternativa para esta finalidade dado que podem resolver problemas a partir de generalização, além de reduzirem os gastos para elaboração de equaç̃̃es volumétricas para este fim. Rodrigues et al. (2010) conclui que as redes neurais artificiais de multicamada direta, podem ser uma excelente alternativa para a estimação do volume comercial de espécies florestais e, contribuir sobremaneira para a eficácia 
da solução desse importante problema.

A validação das equações e das RNAs de melhor desempenho foi realizada a partir do teste Qui- quadrado $\left(x^{2}\right)$ afim de verificar a confiabilidade dos modelos ajustados quando comparados aos valores reais. Os resultados do teste podem ser observados na Tabela 5.

Tabela 5. Validação da equação de Schumacher e melhor RNA através do Teste Quiquadrado a 5\% de probabilidade para a espécie em estudo na Floresta Nacional do Tapajós.

\begin{tabular}{lcrrrr}
\hline UPAs & Equações selecionadas & $\chi^{2}$ (Calculado) & $\begin{array}{c}\chi^{2} \\
\text { (Tabelado) }\end{array}$ & Probabilidade & Situação \\
\hline Todas & Schumacher-Hall & 126,21 & 451,86 & $p \geq 0,05$ & Eq. Validada \\
Todas & RNA 3-10-1 & 126,45 & 451,86 & $p \geq 0,05$ & Eq. Validada \\
\hline
\end{tabular}

De acordo com os resultados obtidos não houve diferença estatística de acordo com o teste Qui-quadrado, portanto, ambos os métodos de quantificação volumétrica testados são válidos para utilização na estimativa volumétrica para a espécie do presente estudo.

\section{CONCLUSÃO}

Ambos os métodos apresentaram estatísticas de ajuste e precisão aceitáveis, com potencial utilização para estimar o volume da espécie
Couratari stellata. No entanto, a RNA mostrou-se ligeiramente superior pela habilidade de aprender e generalizar o conhecimento adquirido sendo, portanto, recomendada para tal finalidade.

\section{AGRADECIMENTOS}

À Universidade Federal do Oeste do Pará e à FAPESPA por ter viabilizado apoio financeiro para a realização deste trabalho. À Cooperativa Mista da Floresta Nacional do Tapajós pela disponibilidade dos dados. 


\section{REFERÊNCIAS}

BARRETO, W.F; LEÃO, F.M; MENEZES, M.C; SOUZA, D.V. Equação de volume para apoio ao manejo comunitário de empreendimento florestal em Anapu, Pará. Pesquisa Florestal Brasileira, v. 34, n. 80, p. 321-329, out./dez. 2014.

BINOTI, M.L.M.S. BINOTI, D. H. B.; LEITE, H. G.; GARCIA, S. L. R.; FERREIRA, M. Z.; RODE, R.; SILVA, A. A. L. da. Redes neurais artificiais para estimação do volume de árvores. Revista Árvore, v. 38, n. 2, p.283-288, 2014.

BRAGA, A. de P.; CARVALHO, A. P. de L. F. de; LUDEMIR, T. B. Redes Neurais Artificiais: Teoria e Aplicações. 2 ed. Rio de Janeiro: LTC, 2007. 260p. BULLINARIA, J. A. Introduction to Neural Computation. Notas de aula. Disponível em:<http://www.cs.bham.ac.uk/ jxb/in c.html>. Acesso em: 11 jan. de 2017.

CAMPOS, J. C. C.; LEITE, H. G. Mensuração florestal: perguntas e respostas. 4 ed. Editora UFV, Viçosa: UFV, 2013. 605 p.

COLPINI, C.; TRAVAGIN, D. P.; SOARES, T. S.; MORAES E SILVA, V. S. Determinação do volume, do fator de forma e da porcentagem de casca de árvores individuais em uma Floresta Ombrófila Aberta na região noroeste de Mato Grosso. Acta Amazônica, Manaus, v. 39, n. 1, p. 97-104, 2009.

CORDEIRO, M. A; PEREIRA, N. N. DE J.; BINOTI, D. H. B.; BINOTI, M. L. M. DA S.; LEITE, H. G. Estimativa do volume de
Acacia mangium utilizando técnicas de redes neurais artificiais e máquinas vetor de suporte. Pesquisa florestal brasileira, Colombo, v. 35, n. 83, p. 255261, jul./set. 2015.

CORDEIRO, T. F et al. Feições de exploração florestal de impacto reduzido na Flona do Tapajós utilizando imagens Landsat e filtros texturais. In: Embrapa Amazônia Oriental-Artigo em anais de congresso (ALICE). In: SIMPÓSIO BRASILEIRO DE SENSORIAMENTO REMOTO. São José dos Campos: INPE, 2017.

DRAPER, N.; SMITH, H. Applied regression analysis. John Wiley e Sons: New York, 706p. 3a edição. 1998.

ESPÍRITO-SANTO, F. D. B.; SHIMABUKURO, Y. E.; ARAGÃO, L. E. O. C. de; MACHADO, E. L. M. Análise da composição florística e fitossociológica da Floresta Nacional do Tapajós com o apoio geográfico de imagens de satélites. Revista Acta Amazônica, Manaus, v.35, n.2, p.155-173. 2005.

GÖRGENS, E. B.; LEITE, H. G.; SANTOS, H. DO N.; GLERIANI, J. M. Estimação do volume de árvores utilizando redes neurais artificiais. Revista Árvore, v.33, n.6, p.1141-1147, 2009.

HAYKIN, S. Redes neurais: princípios e prática. 2ed. Porto Alegre: Bookman, 2001. 900p.

LEAL, F. A.; MIGUEL, E. P.; MATRICARDI, E. A. T.; PEREIRA, R. S. Redes neurais artificiais na estimativa de volume em um plantio de eucalipto em função de 
fotografias hemisféricas e número de árvores. Revista Brasileira de Biometria, v. 33, n. 2, p. 233-249, 2015.

LEITE, H. G.; BINOTI, D. H. B. OLIVEIRA NETO, R. R. DE; LOPES, P. F.; CASTRO, R. R. DE; PAULINO, E. J.; BINOTI, M. L. M. DA S.; COLODETTE, J. L. Redes Neurais Artificiais para a estimação da densidade básica da madeira. Scientia Forestalis, Piracicaba, v. 44, n. 109, p. 149-154, mar. 2016.

MARTINS A. P. M; DEBASTIANI A. B.; PELISSARI A.L.; MACHADO S.A.; SANQUETTA C.R. Estimativa do afilamento do fuste de araucária utilizando técnicas de inteligência artificial. Floresta e Ambiente, Seropédica, v. 24, e20160234, 2017.

MARTINS, E. dos R.; SILVA BINOTI, M. L. M. da; LEITE, H. G.; BINOTI, D. H. B.; DUTRA, G. C. Configuração de redes neurais artificiais para estimação do afilamento do fuste de árvores de eucalipto. Agrária - Revista Brasileira de Ciências Agrárias, v.11, n.1, p.33-38, 2016.

MENDONÇA, A. R. de; PACHECO, G.R.; VIEIRA, G. C; ARAÚJO, M. da S.; INTERMAMNENSE, M. T. Identidade de modelos de estimativa do volume de pinus. Nativa, v.3, n.4, p.281-286, 2015.

OLIVEIRA, R. C. A. de, RODE, R., GAMA, J. R. V., ALMEIDA, E. C. de (2017). Equações volumétricas para Couratari stellata AC Smith (Tauari) na Floresta Nacional do Tapajós. Nativa, v. 5, n. 2, p. 138-144, 2017.
RAMOS, M. Comparação de métodos para estimar o volume comercial em floresta ombrófila densa no estado do Amazonas. Dissertação de mestrado. Universidade Federal do Centro-Oeste. Irati-PR, 2012.

RODRIGUES, E. F.; OLIVEIRA, T. F. DE; MADRUGA, M. R.; SILVEIRA, A. M. DA. Um método para determinar o volume comercial do Schizolobium amazonicum (Huber) Ducke utilizando redes neurais artificiais. Rev. Bras. Biom. v. 28, n. 1, p. 16-23, 2010.

SCHIKOWSKI, A. B.; DALLA CORTE, A. P.; SANQUETTA, C. R. Estudo da forma do fuste utilizando redes neurais artificiais e funções de afilamento. Pesquisa Florestal Brasileira, v. 35, n. 82, p. 119-127, 2015.

SILVA, M. L. M.; BINOTI, D. H. B.; GLERIANI, J. M.; LEITE, H. G. Ajuste do modelo de Schumacher e Hall e aplicação de redes neurais artificiais para estimar volume de árvores de eucalipto. Revista Árvore, Viçosa, MG, v. 33, n. 6, p. 1133-1139, 2009.

SILVA, S; OLIVEIRA NETO, S. N. de; LEITE, H. G; OBOLARI, A. de M. M.; SCHETTINI, B. L. S. Avaliação do uso de regressão e rede neural artificial para modelagem do afilamento do fuste de eucalipto em sistema silvipastoril. Enciclopédia Biosfera, Centro Científico Conhecer- Goiânia, v.13, n.23, p. 189, 2016.

SILVA-RIBEIRO, R.B; GAMA, J.R.V; MELO, L. O. Seccionamento para cubagem e escolha de equações de 
volume para a Floresta Nacional do Tapajós. Cerne, v. 20 n. 4, p. 605-612, 2014.

SOARES, C. P. B; MARTINS, F. B; LEITEJUNIOR, H. U; SILVA, G. F. da; FIGUEIREDO, L. T. M. de. Equações hipsométricas, volumétricas e de taper para onze espécies nativas. Revista Árvore, Viçosa-MG, v.35, n 5, p.10391051, 2011. 